Sierra Leone Journal of Biomedical Research

Vol. 1 (1) pp. 38-43, August, 2009

Original Paper

\title{
Knowledge, Perception of Risk and Attitude of Sierra Leone Military Personnel towards Colleagues with HIVIAIDS.
}

\author{
Sahr Foday ${ }^{1,2}$, Kargbo Brima ${ }^{3}$, Gevao Sahr $M^{4}$, Gbakima Aiah A $^{2}$ and Swarray-Deen Alim ${ }^{1}$ \\ ${ }^{1} 34$ Military Hospital, Wilberforce, Freetown, ${ }^{2}$ Department of Microbiology, College of Medicine and Allied \\ Health Sciences, University of Sierra Leone, ${ }^{3}$ National AIDS Secretariat, Freetown, Sierra Leone, \\ ${ }^{4}$ Department of Haematology, College of Medicine and Allied Health Sciences, University of Sierra Leone, \\ Freetown, Sierra Leone.
}

\begin{abstract}
The aim of this survey was to gain an insight into the level of knowledge, perception of risk and attitude of Sierra Leone Military personnel towards colleagues with HIVIAIDS. Four hundred and fifty (450) randomly selected male and female military personnel including officers and other ranks from six battalions were surveyed with a standard questionnaire. Results of this survey demonstrated a relatively low level of knowledge of HIV and AIDS amongst the survey population as evidenced by the $40 \%$ and $52 \%$ of participants stating that HIV is transmitted by mosquito bites and from public toilets respectively. An equally low perception of risk of the infection was demonstrated from the responses of the participants about attitude towards HIV infected colleagues. Three-fourth of the participants indicated that nobody should be informed if a colleague is HIV positive, with almost all the participants expressing their willingness to take care of an HIVIAIDS person in their household. Varying responses obtained demonstrate the necessity for scaling-up HIV education within the Republic of Sierra Leone Armed Forces. More resources most therefore be made available to the HIVIAIDS office of the Republic of Sierra Leone Armed Forces so that HIV education activities can be extended to all the brigades and battalions.
\end{abstract}

Keywords: Knowledge, Perception, Attitude, HIVIAIDS.

Received 18 February 2009/ Accepted 14 July 2009

\section{INTRODUCTION}

The number of people living with HIV has been found to rise basically due to population growth and, more recently, the effect of the life prolonging effects of antiretroviral therapy. In Sierra Leone, since the first cases of AIDS reported in 1987, various efforts have been made to assess the magnitude of the problem and monitor the trend of the epidemic. Before 2008 available data on HIV in Sierra Leone were scanty. A National Seroprevalence survey conducted in 2002 by Centers for Disease Control and the Government of Sierra Leone (CDC/GOSL) reported a $0.9 \%$ prevalence rate in the country. More recently, National AIDS Secretariat (NAS) and Nimba Research and Consultancy of Ghana reported a $1.53 \%$ prevalence rate with no significant difference observed between male and female prevalence rates (National Seroprevalence Survey Report, 2005).

HIV infection over the years has developed into one of the biggest challenges the world over. The knowledge of the pathogenesis of the infection has proved useful within recent years such that at the present time, noticeable improvements in the concepts of therapy are present (Pistorius et al., 2003). Soldiers are at great risk of HIV infection for multiple reasons. They are usually young, single and sexually active. They are often posted far from home for extended periods resulting in stress and loneliness, which may lead them to casual sex (Rasnake et al., 2005). 
Personnel of the Republic of Sierra Leone Armed Forces (RSLAF) like other militaries are posted to battalions and brigades where they live with other colleagues under strict rules and regulations where continuous social conflicts may occur. In cases where a person is HIV Positive, prejudice behaviour patterns may exist, resulting in severe consequences. It is with this background that the present study was designed to clarify how far knowledge and perception of HIV and AIDS have been addressed in the Sierra Leone Military. The aim of this study was therefore to gain an insight into the level of knowledge, perception of risk and attitude of RSLAF personnel towards colleagues with HIVIAIDS.

\section{MATERIALS AND METHOD}

A two stage random sampling method was done for the selection of participants. Out of a total of 12 battalions located countrywide, six battalions each containing about 400 personnel, were chosen at random. Using the nominal roll of each of the battalions, 75 personnel were chosen making it a total of four hundred and fifty (450) survey participants. A standard pretested questionnaire drawn in English was used as the survey instrument and all questions were translated into the local pigeon English for those who could not understand English. A face to face interview was done for all the participants upon obtaining a verbal informed consent. The questionnaire which contained only closed-ended questions included questions about their knowledge about HIV and AIDS, perception of high-risk activities, and attitude towards persons living with HIVIAIDS. Miscellaneous questions about the demographic profile of the participants were included at the beginning of the questionnaire

\section{RESULTS}

The mean of the 450 personnel who participated in the survey was 27years. Four hundred and thirty five (435) were males and only 15 were females. $87 \%$ of the participants were between 20 and 39 years old and $13 \%$ were between 40 and 59 years old. $88 \%$ of the study population was married and only $10 \%$ of the surveyed subjects were officers at the time of the survey. $39 \%$ of the survey participants had attained only Primary School Education, $23 \%$ had attained a Secondary education and $8 \%$ had a University degree. Thirty percent $(30 \%)$ of the survey participants indicated that they did not have any formal schooling.

\section{Knowledge about methods of HIV transmission}

From table 1 , the vast majority of the survey participants believed unprotected sex $(97 \%)$ and blood transfusion (86\%) as the commonest methods of HIV transmission. Followed closely were the use of unsterilized blades and needles $(75 \%)$ and kissing (69\%) as common methods of HIV transmission. Coughing and sneezing by an HIV positive person, (54\%) sharing of public toilet with HIV positive persons (52\%) and mosquito bites $(40 \%)$ were mentioned as methods of HIV transmission by the survey participants. None of the survey participants knew that HIV could be transmitted from mother to child through breast milk, and only $4.5 \%$ and $9.0 \%$ thought HIV could be transmitted by sharing meals or shaking hands respectively with an HIV infected person.

Table 1: Summary of the Perception of HIV transmission by Participants Selected

\begin{tabular}{lc}
\hline Methods & \% agreeing \\
\hline Mother to child through breast-feeding & 0 \\
Sharing meals & 4.5 \\
Handshake & 9.9 \\
Mosquito bite & 40 \\
Use of public toilets & 52 \\
Coughing / sneezing & 54 \\
Kissing & 69 \\
Use unsterilized blades and needles & 75 \\
Blood transfusion & 86 \\
Unprotected sex & 97 \\
\hline
\end{tabular}


Table 2: Number of sexual partners by participants in the last six months

\begin{tabular}{lc}
\hline No. of sexual Partners & \% of Participants \\
\hline 1 sexual partner & 9.0 \\
2 sexual partners & 22.5 \\
3 sexual partners & 57.0 \\
$\geq 4$ sexual partners & 13.5 \\
\hline
\end{tabular}

Table 3: Responses of Participants to condom use during previous sexual contact sexual behaviour of Participants

\begin{tabular}{lc}
\hline Responses & \% agreeing \\
\hline Partner objected & 17.5 \\
Do not like them & 32.0 \\
Did not think it was necessary & 27.5 \\
Did not think of it & 23.0 \\
\hline
\end{tabular}

Questions on the sexual behaviour of participants included the number of sexual partners over the past 6 months, why condom was not used during the last sexual contact, and previous HIV testing. Only $9 \%$ of the participants had one sexual partner in the last 6 months, $57 \%$ of the participants on the other hand had 3 sexual partners in the period under review, with $22.5 \%$ having 2 sexual partners and $13.5 \%$ having 4 sexual partners during the same period (Table 2). Overall 396 of the 450 participants (88\%) were either married or co-habiting with a partner at the time of survey.

When asked on the use of condom with someone besides their regular sexual partner during their last sexual contact, only $11 \%$ agreed that they did use condom in their last sexual contact. Of the 401 who did not use condom in the last sexual contact $17.5 \%$ expressed that their partners objected to the use of condom. $32 \%$ stated that they themselves did not like using them, whilst $27.5 \%$ thought it wasn't necessary. $23 \%$ stated that they did not think about it (Table 3). When asked about previous HIV testing, $70 \%$ of the survey participants stated that they have never tested for HIV. Of the $30 \%$ who have done the HIV test before, only $2 \%$ had done it within the 12 months that preceded the survey. $13 \%$ stated that they did the test 1-2 years ago, and 55 did the test 2-3 years ago. $10 \%$ of the survey participants expressed that they did the HIV test more than 3 years ago (Figure 1).

Table 4: What participants think should happen to a colleague infected with HIV.

\begin{tabular}{cc}
\hline If a colleague is infected with HIV: & Frequency \\
\hline He/She should be suspended from the service & 9.0 \\
The whole unit should be informed & 11.5 \\
Nobody should know about it & 75.0 \\
He/she should be isolated & 4.5 \\
\hline
\end{tabular}

\section{Contact with HIV infected colleagues}

Enquiring about participants' attitude towards HIVIAIDS colleagues, $100 \%$ admitted that they would take care of an HIVIAIDS person in their household. $95 \%$ agreed that HIVIAI

DS patients should be allowed to work, whilst only $40 \%$ expressed that they would sleep together with an infected colleague. Asked about shaking hands and eating together with an HIV positive knowledge, $85 \%$ and $90 \%$ expressed that they would shake hand and eat together respectively with an HIV positive colleague. Only $10 \%$ of the survey participants stated that they would share clothes with an HIV infected colleague (Figure 2). Asked about what participants think should happen to a colleague infected with HIV, $75 \%$ said nobody should know about it. $11.5 \%$ said the whole unit should be informed, whilst $9 \%$ said the HIV positive person should be suspended from the service. Only $4.5 \%$ expressed that the HIV infected colleague should be isolated (Table $4)$. 


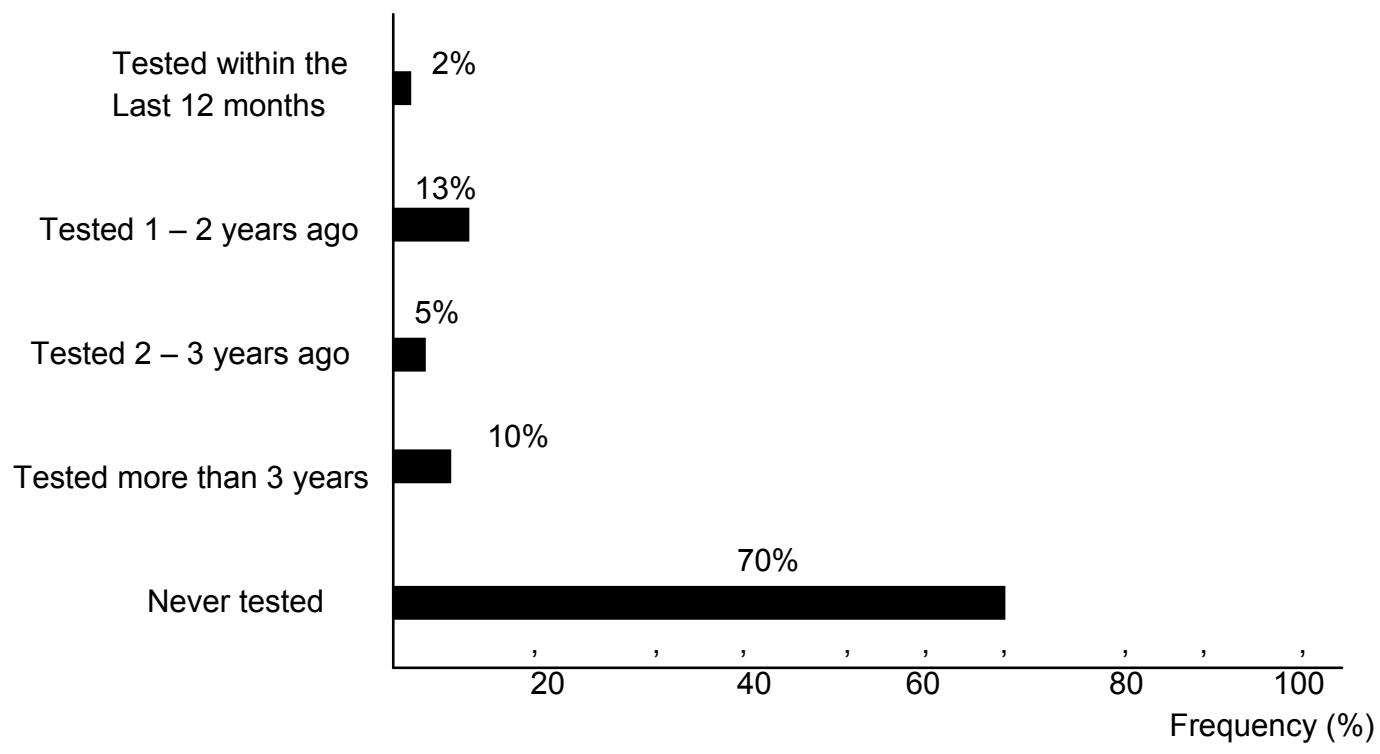

Figure 1: Frequency distribution of previous HIV testing by participants

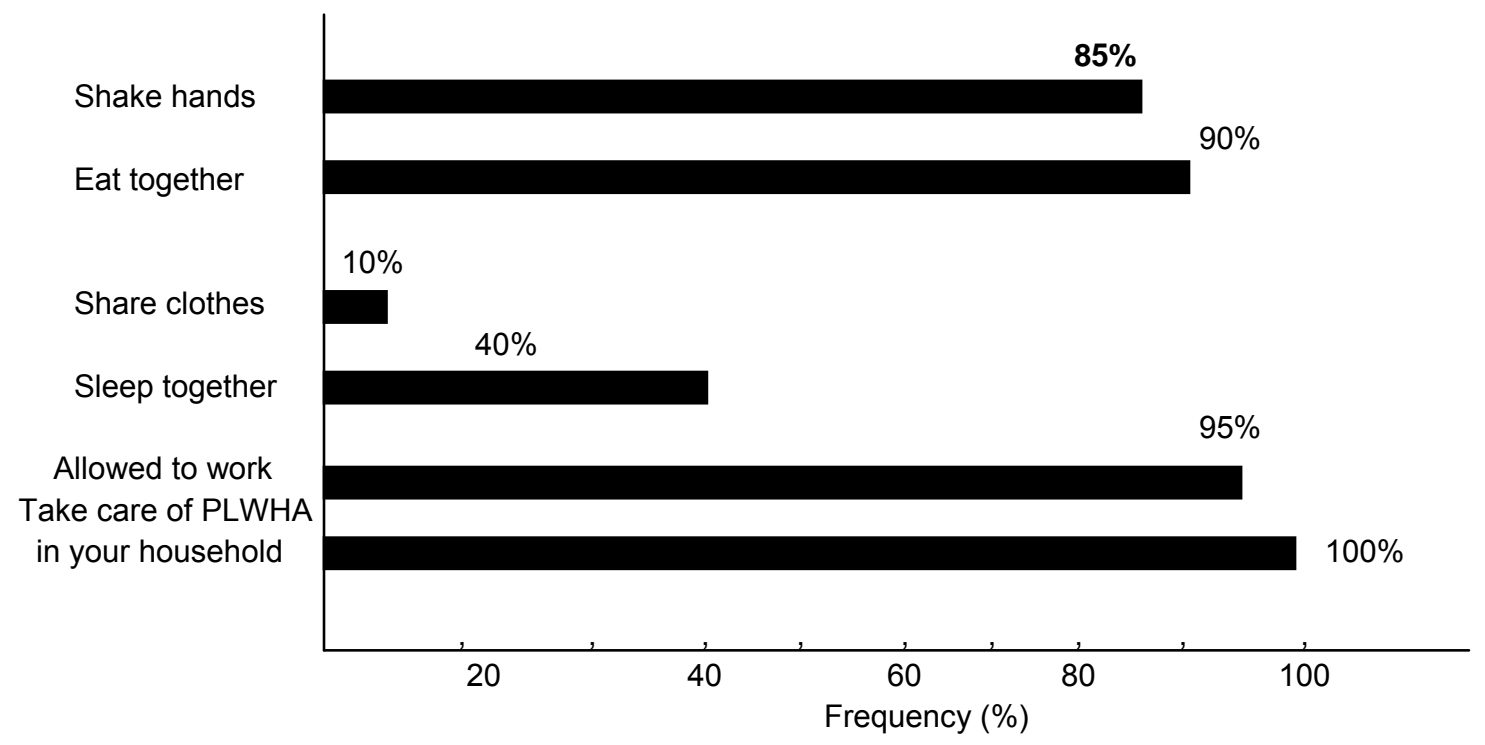

Figure 2: Frequency distribution of attitude of Participants towards HIVIAIDS Patients

\section{DISCUSSION}

Results of this survey show that amongst the military in Sierra Leone the level of knowledge of HIVIAIDS and perception of risk of acquiring the disease were relatively low. There is evidence that exposure to information about AIDS significantly reduces the risk of infection (Sweat et al., 1995). Behavioural interventions are recognized ways of preventing sexually transmitted diseases including HIV (Booth-Ke wly, 2002; Emmerson, 1997). HIV, like other sexually transmitted diseases have posed a threat to military personnel throughout history. In addition to their treatment, prevention through information and education has been suggested as reliable means of controlling their spread (Rasnake et al., 2005). The selection of the survey sample with regards to the level of education was relatively balanced. Comparatively, there is high representation of the $20-39$ years old soldiers compared with their counterparts in the $40-59$ years age group. This means that those in the younger age group within the military should be targeted in the HIV activities of the HIVIAIDS prevention program.

From the results of this survey, the participants had a fairly good knowledge of the realistic methods of HIV transmission. $97 \%$ knew that HIV can be transmitted through unprotected sex, and $86 \%$ and $75 \%$ knew that HIV could be transmitted by blood transfusion and unsterilized blades and

needles respectively. Similarly, a survey conducted among soldiers of the UnteroffizierKruger-Kaserne barracks in Kusel, Germany reported that a $100 \%$ agreement with the statement that sexual contact was the primary 
means of HIV transmission (Pistorius et al., 2003). Although they did not consider unsterilized blades and needles in their list of methods of HIV transmission, blood transfusion also ranked high $(99 \%)$ amongst the responses in their survey. Unlike the German cohort that recognized breastfeeding as a realistic method of HIV transmission, none of our survey participants recognized mother to child transmission through breast milk as a method of HIV transmission.

A number of fictive methods of HIV transmission amongst our survey population ranked high. $69 \%$ thought HIV could be transmitted by kissing and $54 \%$ were of the opinion that HIV could be transmitted by coughing or sneezing. Mosquito bites, hand shake and sharing meals with HIV positive persons were also suggested as methods of HIV transmission. Newman et al. (2001) reported that within the military in Mozambique over $50 \%$ of the personnel recognized mother to child transmission of HIV. A similarly high percentage suggested from their study that HIV could be transmitted by kissing. These responses suggest that knowledge of HIV transmission among the survey participants was low. A greater willingness was however expressed by survey participants to learn about HIV and other sexually transmitted diseases. The success of information and education methods designed specifically for soldiers have been demonstrated (Emmerson 1995; Booth-Kewly et al., 2002).

In this study, many respondents participated in risky sexual activities. This was evaluated by their responses to the number of sexual partners they have in the last 6 months, condom use during last sexual contact and previous HIV testing. Over $70 \%$ of the survey participants have had three or more sexual partners over the last 6 months. This result indicates some degree of promiscuity within the study population. Unprotected sex is an established method of HIV transmission. $89 \%$ of the survey participants failed to use condom in their last sexual contact, which is considered a high-risk behaviour. Behavioural interventions have been shown to reduce rates of unprotected sexual intercourse in a number of population

groups (Kelly et al., 1989; Rotheram-Borus et al., 1991; Jemmott et al., 1992). Several reports indicate that although not all interventions have an effect on behaviour, changes in risky behaviour can occur as a result of well-designed intervention like HIV education and condom promotion (Holtgrave et al., 1995; Oakley et al., 1995).
Survey participants provided varying responses about their attitude towards HIV infected colleagues from taking care of an HIV infected colleague to suspension from service. Threefourth of the participants stated that if a colleague is HIV positive, nobody should know about it. Only $11.5 \%$ suggested that the whole barracks should be informed. Pistorius et al. (2005) suggested that demands of mandatory disclosure are based on diffused fear and lack of understanding of the disease. $11.5 \%$ of the survey participants demanded that the whole barracks must be informed. Surveys about the discrimination of HIV infected individuals in the armed Forces do exist (Feldman, 1998). Responses obtained from our survey participants on their attitude towards HIV positive colleagues clearly suggest some amount of personnel discrimination against HIV positive individuals.

The wide spectrum of responses on the subject of HIV transmission, perception of risk and attitude towards HIV infected colleagues demonstrate the necessity for scaling-up HIV education within the Republic of Sierra Leone Armed Forces. The HIV/AIDS program of the Republic of Sierra Leone Armed Forces is presently carrying out HIV education and condom distribution amongst the troops in the various brigades and battalions. All the activities of this program are presently supported by the Department of Defence of the American Embassy in Sierra Leone, and the United Nations Fund for Population Activities (UNFPA) office in the country. It is therefore recommended that funding for HIVIAIDS education activities within the Republic of Sierra Leone Armed Forces must be increased so that troops in all the brigades and battalions countrywide can be reached and educated on the disease. Results of this study was however interpreted with caution as the responses given by participants in the six battalion surveyed may not reflect the knowledge and perception of the disease of the entire Sierra Leone Military located in three brigades and twelve battalions up country and in the various minor units located in Freetown. 


\section{REFERENCES}

Booth-Kewly S, Minagawa RY, Shoffer RA and Brodine, SK (2002). A behavioural intervention to prevent sexually transmitted diseases/Human Immunodeficiency Virus in a Marine Corps sample. Mil. Med. 167: $145-150$.

Boyer CB, Shafer MA, Shaffer RA, Brodine SK, Ito SI, Yniguez DL, Benas DM and Schachter J (2002). Prevention of sexually transmittedsease and HIV in young military men: evaluation of a cognitive-behavioural skills building intervention. Sex Transm. Dis. 28349 - 355.

Emmerson LA (1997). Sexually transmitted diseases control in the Armed Forces, past and present: Mil. Med. 162: 87 -91

Feldman EA (1998). Testing the Force: HIV and discrimination in the Australian Military. AIDS Public Policy J. 13: 55 - 90

Holtgrave DR, Quall NL, Curran JW, Valdiserri RO, Guinan ME and Parra WC (1995). An overview of the effectiveness and efficiency of HIV Prevention Programs. Public Health Rep. 110: $134-49$.

Jemmott JB, Jemmott LS and Fong GT (1992). Reduction of HIV risk: associated sexual behaviours among black male adolescents: Effects of an AIDS Prevention intervention. Am. J. Public Health. 82: $372-7$

Kelly JA, St. Lawrence JS, Hood HV and Brasfield TL (1989). Behavioural intervention to reduce AIDS risk activities. J. Consult. Cein. Psycol. 57: $60-7$

National HIV Seroprevalence Survey (2005). GOSL/Nimba Research and Consultancy.

Newman CM, Miguel F, Jemisse BB, Macome AC and Newman RD (2001). HIV seroprevalence among military blood donors in Manica Province, Mozambique. Int. J. STD AIDS. 12: 225 - 228

Oakley A, Fullerton D, and Holland J (1995). Behavioural Interventions for HIVIAIDS Prevention. AIDS. 9: 479 - 86

Peterson JL, Coates TJ et al. (1996). Evaluation of an HIV risk reduction intervention among African-American homosexual and bisexual men. AIDS. 10: $319-25$

Pistorius A., Gergan G and Willershausen B (2003). Survey about the knowledge of the HIV infection amongst recruits of the German military. Eler. J. Med. Res. 8: $154-160$

Rasnake MS, Conger NG, McAllister $\mathrm{C}$ et al. (2005). History of U.S. military contributions to the study of Sexually Transmitted Diseases. Mil. Med. 170: $61-65$

Rotheram-Borus MJ, Koopman C, Haignere C and Davies M (1991). Reducing HIV sexual risk behaviours among runaway adolescents. JAMA. 266: $1237-41$

Sweat MD, Nopllesorn T, Mastro TD, SangKharomya S et al. (1995). AIDS awareness among a cohort of young Thai men: Exposure to information, level of knowledge, and perceptional risk: AIDS Care. 7: $573-591$ 